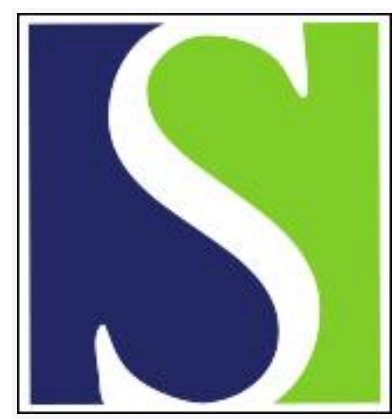

Scand J Work Environ Health 2014;40(2):146-155

https://doi.org/10.5271/sjweh.3395

Published online: 25 Oct 2013, Issue date: 01 Mar 2014

The effects of rest breaks, work shift start time, and sleep on the onset of severe injury among workers in the People's Republic of China

by Lombardi DA, Jin K, Courtney TK, Arlinghaus A, Folkard S, Liang Y, Perry MJ

Few studies have evaluated the effect of rest breaks on preventing the adverse effects of fatigue, such as work-related injury. This study provides empirical evidence that rest breaks of any duration allow for significantly longer work time without injury, which is importantly modified by shift start time. Thus, frequent rest breaks enhance worker safety and allow for recuperative rest.

Affiliation: Center for Injury Epidemiology, Liberty Mutual Research Institute for Safety, 71 Frankland Road, Hopkinton, MA 01748, USA. david.lombardi@libertymutual.com

Refers to the following texts of the Journal: $2010 ; 36(2): 109-121$ 2011;37(3):173-185 2012;38(2):163-170 2012;38(6):560-567

Key terms: China; epidemiology; fatigue; injury; occupational injury; People's Republic of China; rest break; shift work; sleep; sleep duration; sleep quality; work shift

This article in PubMed: www.ncbi.nlm.nih.gov/pubmed/24162622

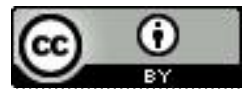




\title{
The effects of rest breaks, work shift start time, and sleep on the onset of severe injury among workers in the People's Republic of China
}

\author{
by David A Lombardi, PhD, 1, 2 Kezhi Jin, PhD,3, 4, 5 Theodore K Courtney, MS, CSP,1, 2 Anna Arlinghaus, \\ PhD, 1, 2, 6 Simon Folkard, DSc, 8 Youxin Liang, MD, PhD, 3, 4, 5 Melissa J Perry, ScD, MHS ${ }^{9}$
}

\begin{abstract}
Lombardi DA, Jin K, Courtney TK, Arlinghaus A, Folkard S, Liang Y, Perry MJ. The effects of rest breaks, work shift start time, and sleep on the onset of severe injury among workers in the People's Republic of China. Scand J Work Environ Health. 2014;40(2):146-155 doi:10.5271/sjweh.3395
\end{abstract}

\begin{abstract}
Objective The aim of the present study was to investigate the effects of the duration and timing of rest breaks on traumatic injury risk across a shift in a relatively large sample of hospitalized workers with severe work-related hand injury in the People's Republic of China (PRC).
\end{abstract}

Methods Hospitalized workers from multiple industries with severe work-related traumatic hand injury were recruited from 11 hospitals in three industrially-developed cities in the PRC: Ningbo, Liuzhou, and Wuxi. Cox regression was used to compare time into the work shift of injury across categories of rest breaks, while evaluating several potential covariates including age, gender, work hours, work start time and duration, injury day and time, duration and quality of last sleep, alertness/sleepiness, job control, and several transient work-related factors. Effect modification by work shift start time was also evaluated.

Results With four days of injury, 703 hospitalized workers completed a face-to-face interview. After adjusting for significant covariates, workers with rest breaks of 1-30, 31-60, and >60 minutes were able to work significantly $(\mathrm{P}<0.001)$ longer into their work shift without an injury $(>5$ hours) than those with no rest break. A significant interaction was also observed between rest break status and start time of the work shift.

Conclusion The results of this study suggest that rest breaks of any duration have a significant effect on delaying the onset of a work-related injury, which is modified by the time of day in which a shift begins.

Key terms epidemiology; fatigue; occupational injury; sleep duration; sleep quality.

As in many countries, work-related traumatic injuries are an important and preventable public health and economic concern in the People's Republic of China (PRC), and fatigue due to long work hours and shifts schedules within continuous operations has been suggested as a potential cause (1-4). In a recent study of 3479 frontline workers in 60 factories over a two-year period (2008-2009) in Shenzhen, China (4), 8.3\% of all workers reported having a traumatic injury in the previous 12 months, and the strongest risk factors were working $>55$ hours per week [odds ratio (OR) 1.64, $95 \%$ confidence interval $(95 \% \mathrm{CI}) 1.21-2.22]$ and high mental work stress. Among traumatic injuries, acute injury to the hand is one of the most frequently reported in the PRC. According to a decade summary of epidemiological studies (1994-2005), between $23-54 \%$ of all emergency room visits during this period in the PRC were for hand injuries (5-6).

1 Center for Injury Epidemiology, Liberty Mutual Research Institute for Safety, Hopkinton, MA, USA.

2 Department of Environmental Health, Harvard School of Public Health, Boston, MA, USA.

3 School of Public Health, Fudan University, Shanghai, People's Republic of China (PRC).

4 Key Laboratory of Public Health Safety, Ministry of Education, Fudan University, Shanghai, PRC.

5 WHO Collaborating Center for Occupational Health, Fudan University, Shanghai, PRC.

6 Gesellschaft für Arbeits-, Wirtschafts- und Organisationspsychologische Forschung (GAWO) eV, Oldenburg, Germany.

7 Institut de Psychologie, Université Paris Descartes, Paris, France.

8 Department of Psychology, Swansea University, Swansea, UK.

9 George Washington University School of Public Health and Health Services, Washington, DC, USA.

Correspondence to: David A Lombardi, Principal Research Scientist, Center for Injury Epidemiology, Liberty Mutual Research Institute for Safety, 71 Frankland Road, Hopkinton, MA 01748, USA. [E-mail: david.lombardi@libertymutual.com] 
Fatigue can be considered as a global concept, which includes the subfactors of sleepiness and mental, physical, and muscular fatigue, and can be defined as "a biological drive for recuperative rest" (7). The bipolar dimension of alertness/sleepiness is influenced by factors such as circadian and homeostatic effects (eg, time of day, time awake, and periods of rest and sleep). Among workers, overall fatigue is also affected by the physical and mental efforts of their assigned work tasks as well as specific components of their work schedules, such as the number of hours worked, rest breaks, and the timing of consecutive shifts (eg, night work and rotating shift work) (8-9). If not carefully managed, the synergy among these factors may lead to an accumulation of overall fatigue with the potential for significant performance impairment, error-risk, or ultimately an injury or "accident" during their workday or journey home (7-14). Several studies have shown the potential protective (ie, "recuperative") effects of supplemental rest breaks within a shift and time-off between shifts, including significant reductions in fatigue and pain and increased productivity (15-20). For example, very short rest breaks (eg, between 3-9 minutes per hour) have been shown to reduce musculoskeletal discomfort and strain in physically demanding work settings, such as meat processing and agricultural work (15-16), and computer-related work (17-19). Likewise, brief, regularly scheduled, mild physical activity and social breaks (7-minutes spaced hourly) have shown to be an effective in-flight fatigue countermeasure, by reducing physiological and subjective sleepiness for up to 15-25 minutes after a break (most effectively near the circadian trough) (20). In another study, short rest pauses (10-minute rest pause with brief neck-shoulder exercise were compared with a single recovery night after a previous night of short sleep, and two successive nights of "normal" (eight hours) sleep. This study reported that short rest pauses improve performance and subjective sleepiness, regardless of the amount of prior sleep, but only for a brief amount of time ( 15 minutes). Thus, it is concluded that rest pauses are not effective in obtaining longer "recuperative" effects (21).

Fewer non-laboratory field studies have examined the impact of rest breaks in preventing or reducing the potential adverse effects of fatigue for traumatic outcomes such as work-related injury or "accidents" (22-27). The primary measure(s) in these studies are the presence or absence of a rest break during the work shift (22-24) or the longer breaks between work shifts (25), and typically not the duration or time of day that the rest breaks occurred. For example, Tucker et al (22-24) reported that work-related injury risk across a shift substantially decreases after a rest break; however this effect may differ across work environments and the authors caution that although rest breaks are effec- tive in most industrial-based field studies, there may be potential for increasing risk when scheduling additional rest breaks for workers performing tasks where stopping and starting up the process may increase injury risk (22). Among analytic studies, a case-control study among wood processing plant workers reported that one significant risk factor they observed for work-related injury was the inability to take a rest break (26).

More recently, a study by Arlinghaus et al (27) examined the effect of the timing of rest breaks on injury risk within a shift and demonstrated that longer accumulated rest break durations allowed for a significantly longer time before injury (ie, fall from ladder) than workers with no rest break or shorter break durations prior to their fall. This study was limited by a relatively moderate sample size and homogeneous workplace exposures (ie, 306 worker falls from a ladder primarily in construction), thus it is not clear whether the protective effects of rest breaks can be generalized to other injury types (such as traumatic hand injury), occupational settings (eg, manufacturing), or if the duration of rest breaks or the starting time of the work shift impact the effects of a break on fatigue. Additionally, it is unclear if factors such as sleep duration and quality prior to a work shift or alertness/sleepiness at the time of an injury influence the effects of rest breaks. The efficacy of single longer rest breaks ( $>60$ minutes) has also not been evaluated nor is it known if the effect of shorter breaks is as effective or if a threshold exists for additional benefits (eg, recovery from work-related strain and fatigue might set in after a certain rest time, and resting longer might not add further benefits).

The aim of the present study was to investigate the effects of the duration and timing of rest breaks on onset time of a traumatic injury within a shift among a relatively large sample of workers in various industries, hospitalized with a severe work-related hand injury in the $\operatorname{PRC}(5,6)$. The primary research questions pursued in this study were: (i) are work rest breaks associated with a significant delay in the onset time of a work-related injury and is this modified by the circadian timing of the start of the shift? (ii) are longer rest break durations associated with an increase in time worked until injury (ie, time-on-task)? and (iii) are the effects influenced by other fatigue-related covariates, such as sleep duration?

\section{Methods}

\section{Study sample and questionnaire}

Study subjects were recruited from workers admitted for treatment of a sudden-onset, traumatic injury to the fingers, hand, or wrist in two hand-surgery and nine general hospitals in three industrially-developed 
cities in the PRC: Ningbo (Zhejiang Province), Liuzhou (Guangxi Zhuang Autonomous Region), and Wuxi (Jiangsu Province). Over a two-year period, while in the hospital, 730 hand-injured workers were approached for a face-to-face interview; 27 were either unavailable or refused to participate, thus 703 subjects (96.4\%) completed the study and were included in this analysis. Study inclusion criteria and interview procedures have previously been reported $(5,6)$. In summary, a clinician verified that there was one or more injuries to the fingers, hand, or wrist (including a laceration, crush, avulsion, puncture, fracture, contusion, amputation, or dislocation) and that the injury was work-related. After obtaining informed consent, an interviewer - trained in human research participant protection, governmental regulations, interview techniques, and data coding - conducted a face-to-face interview at the hospital using a structured questionnaire administered in Chinese (cross-translated) (28).

The instrument was designed primarily to collect data on transient work-related exposures preceding the onset of a traumatic hand injury $(6,29)$ and compare exposures relating to the work environment, work equipment, work practices, and worker-related factors occurring during the "hazard"-to-control period. The primary data for the current analysis was collected to evaluate the impact of rest breaks on injury occurrence and included specific questions on work scheduling, break times, and other fatigue-related factors, while also integrating work-related "hazard" period transient exposures as covariates. For each worker, the primary data included (i) the time of day and day of week of the injury, (ii) the work start and scheduled work end time on injury day as well as the two days prior to the injury, (iii) the frequency and timing of each rest break, (iv) current and previously scheduled working hours, (v) sleep duration and sleep quality in three previous sleeps to the injury, and (vi) alertness/sleepiness (using the Karolinska Sleepiness Scale) at the time of injury and in previous days.

The Liberty Mutual Research Institute for Safety Institutional Review Board, the Fudan School of Public Health Institutional Review Board, and the Harvard School of Public Health Human Subjects Committee approved the study.

Demographic characteristics, work-related factors, and time into the shift

Among worker-related and work-schedule factors, age, gender, total number of days worked and work hours, scheduled length of the shift, shift start time, time of day of injury and a measure of job control were analyzed. Shift start time was initially categorized into three times of the day: the morning (06:00-13:59 hours), late afternoon (14:00-21:59 hours), and night (22:00-05:59 hours). Due to the limited number of workers starting their shifts in the late afternoon $(\mathrm{N}=89)$ and night $(\mathrm{N}=42)$, these were combined (14:00-05:59 hours) for comparisons with the workers starting in the morning. Time into the work shift (proxy for time on task) was calculated by subtracting the reported time at which the injury occurred from the work shift start time (hour: minute), yielding the total amount of time worked until the injury occurred. So that only relevant work time into the shift was included, this estimate was adjusted by subtracting the total reported break time before the injury from time into the shift. Job control was measured with a single question with the levels: "selfpaced", "non-self-paced" including "machine-paced", "incentive-based", and "quota/time-based". In addition, transient factors related to the work environment, equipment, and practices evaluated as covariates included exposure at that time of injury to using malfunctioning machinery, tools, or work materials; performing a task with a different method; performing an unusual work task; being distracted; rushing; feeling ill; and wearing gloves (6).

\section{Rest break duration}

Each worker was asked when their shift began and was scheduled to end on the day of their injury; also, if they took any rest break(s) on this day (as well as the preceding two days in separate questions) along with the exact start and end time of each reported break. Break duration was calculated from the difference between their start and end time (eg, "break 1 end-start: 10:15-10:00 hours, thus a duration of 15 minutes"), and the number of breaks was enumerated as was the total accumulated break time (up to two breaks were collected per worker per day) taken prior to the injury.

\section{Sleep duration, quality, and alertness/sleepiness}

Each worker was asked, "What time did you fall asleep and what time did you wake up directly on the day (or night) of the injury?" The total sleep duration was calculated as the amount of sleep obtained between onand offset of sleep. Workers were also asked when they normally fell asleep and woke up. A follow-up question was asked regarding their sleep quality directly before the injury (as well as their usual sleep): "During this time, how well did you sleep?" Subjective sleep quality was assessed using a self-reported 5-point scale as: $1=$ "extremely badly", 2="quite badly", $3=$ "in between", 4= "quite well", 5="extremely well". Due to the limited number of cases in the extremes of this scale, prior to data analysis the data was collapsed into three categories as: "slept badly", "in between", and "slept well". Using 
the KSS, workers were also asked about their alertness/ sleepiness: "How alert or sleepy did you feel at the time of your injury?"

\section{Statistical analysis}

Demographic characteristics for workplace and temporal factors, such as time of day, time into the shift, scheduled work hours, and total rest break duration were summarized using descriptive statistics. Accumulated total break time was categorized into no breaks and 1-30,31-60, and $>60$ minutes based on the aim of evaluating the effects of a short, medium, and longer break times on the time-to-injury. Work-related injury risk across time into the shift was then estimated and compared among workers with and without rest break(s), as well as within each rest break category. To estimate median time into the shift by rest break time, unadjusted stratified Kaplan-Meier analysis was conducted $(30,31)$.

Cox regression (32) was used to estimate the association between rest break status and the time into the work shift of the injury (eg, the accumulated or cumulative percent of workers without an injury at each time interval), while evaluating the following covariates: age, gender, total weekly work hours, shift start time, scheduled shift length, time and day of injury, sleep duration and sleep quality before the injury, and alertness/sleepiness at the time of injury. In addition, seven transient work-related exposures at the time of injury were evaluated as covariates that include using malfunctioning machinery, tools, or work materials; performing a task with a different method; performing an unusual work task; being distracted; rushing; feeling ill; and wearing gloves (6). Injury incidence was denoted as the event of interest, and time into the work shift as the time variable. Cumulative survival across time into the shift, hazard ratios (HR), where the HR is the ratio of the rate at which the event occurs and a lower HR indicates a longer time of event-free survival, and $95 \%$ confidence intervals $(95 \% \mathrm{CI})$ were estimated for breaks versus no breaks and for each rest break category. Due to the within-subject nature of this case-crossover study $(6,29,33)$, all individuals experienced an injury during their workday, and thus all cases had an outcome event (non-censored data). To evaluate effect modification by shift start time, we used a similar Cox regression model comparing those starting their shift in the morning and earlier in the day (06:00-13:59 hours) to workers starting later in the afternoon or night (14:00-05:59 hours), after controlling for age, gender, weekly work hours, shift duration, day of injury, last sleep quality, and rushing at the time of injury. All statistical analyses were conducted with SAS version 9.2 (SAS Institute, Cary, NC, USA).

\section{Results}

\section{Worker characteristics}

Worker characteristics are presented by category of accumulated break duration on the day of injury in table 1. Among the 703 injured workers, 527 (75.0\%) were male, with a mean age of $31.8(95 \%$ CI 31.0-32.6) years. Descriptive details of this study sample have been published elsewhere (6); in summary, workers were rapidly interviewed post injury in the hospital with $86 \%$ being interviewed within two weeks (median of four days) of their injury. The nature of injury was generally severe [39.1\% involving crushes, amputation (18.9\%), laceration (16.7\%), fracture (12.1\%), and avulsion (8.2\%)] with powered machines involved in $59.5 \%$ of the injuries. Males worked mostly in occupations related to machinery, fabricated metal, basic metal, and wood products, whereas females had a greater representation in plastics, food products, textiles, and publishing. Less than $32 \%$ of workers had prior safety training and $44 \%$ reported having a safety officer supervising their workplace. The distribution of the day of the week of these injuries was relatively uniform; however, the peak was Saturday (15.7\%) with the lowest proportion occurring on Thursday (11.3\%).

\section{Work schedule and rest breaks}

The percentage of workers scheduled by time of the workday presented in figure 1 shows that most workers $(>70 \%)$ were scheduled to work between 08:00-18:00 hours; however, at least $30 \%$ of the workers in this study started their work day at 06:00 hours and others were scheduled to work up until 20:00 hours. Mean scheduled shift length among all workers was $9.6(95 \% \mathrm{CI}$ 9.4-9.7) hours. With regards to rest breaks, among the 703 workers, 432 (61.4\%) reported having one or more rest breaks prior to their injury (see table 1). Among these, 385 reported a single rest break and 47 reported having two breaks. The mean and median accumulated total break duration for workers who had rest was 0.84 [standard error of the mean (SEM) 0.04] and 0.5 hours, respectively. When categorized by duration (see table 1), $271(38.6 \%)$ workers had no rest-break time, $89(12.7 \%)$ had accumulated rest break times from 1-30 minutes, 163 (23.2\%) from 31-60 minutes, and 180 (25.6\%) workers had $>60$ minutes of break time. Scheduled shift length (hours) for workers slightly increased across categories of accumulated rest break times, with an overall mean of 9.6 (95\% CI 9.4-9.7); however, workers without a scheduled rest break had a slightly (but significantly) shorter scheduled work day than those with rest breaks of 31-60 or $\geq 60$ minutes. Among all workers, $8.3 \%$ reported working overtime at the time of injury (6). 


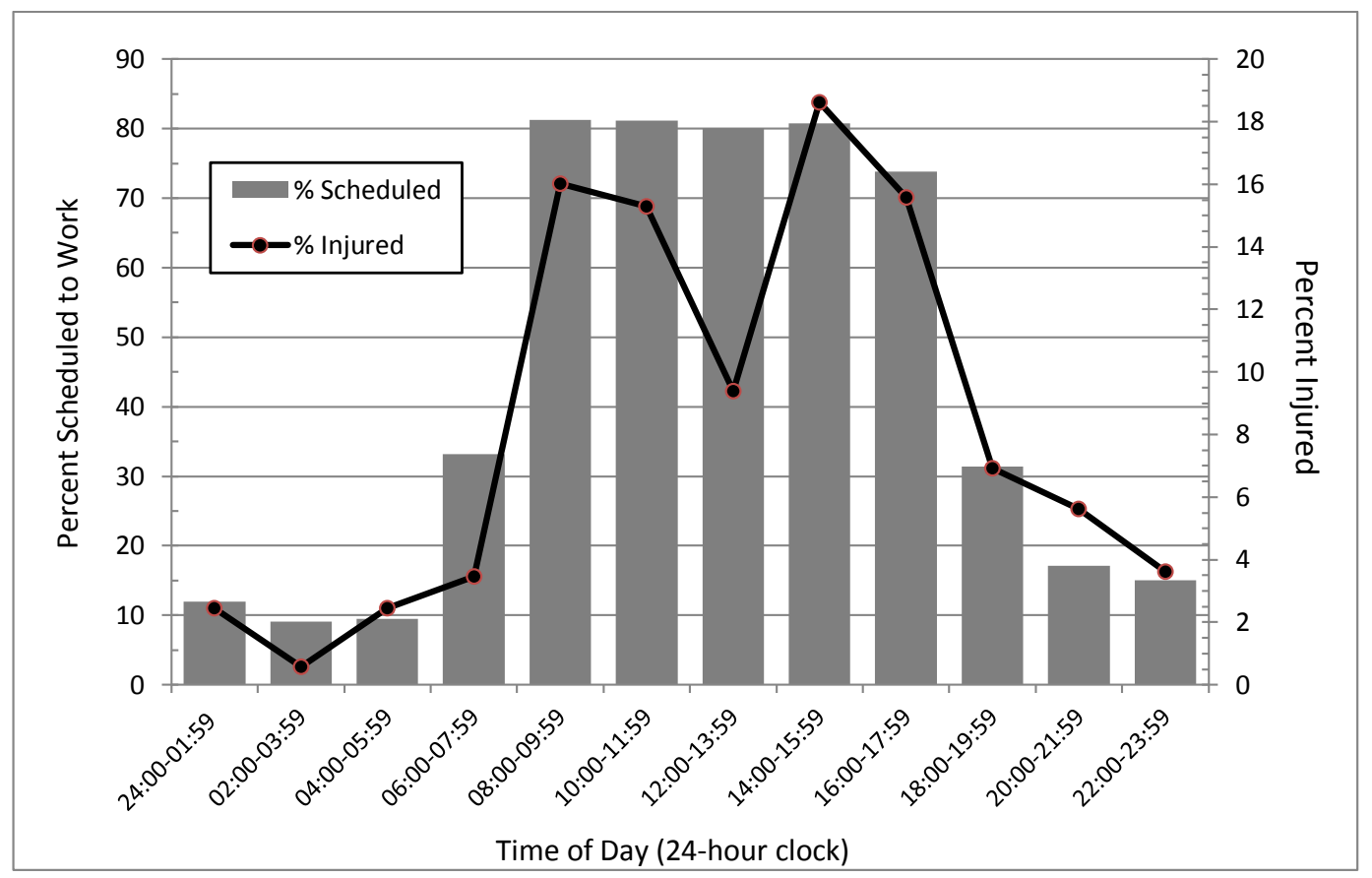

Figure 1. Percent of workers scheduled and injured by time of day (24-hour clock).

Table 1a. Distribution of gender by total accumulated break time prior to the injury.

\begin{tabular}{|c|c|c|c|c|c|c|c|c|c|c|}
\hline & \multicolumn{2}{|c|}{ No break } & \multicolumn{2}{|c|}{ 1-30 minutes } & \multicolumn{2}{|c|}{$31-60$ minutes } & \multicolumn{2}{|c|}{$>60$ minutes } & \multicolumn{2}{|c|}{ Total } \\
\hline & $\mathrm{N}$ & $\%$ & $\mathrm{~N}$ & $\%$ & N & $\%$ & $\mathrm{~N}$ & $\%$ & N & $\%$ \\
\hline Total & 271 & 38.6 & 89 & 12.7 & 163 & 23.2 & 180 & 25.6 & 703 & 100.0 \\
\hline Male & 201 & 38.1 & 56 & 10.6 & 129 & 24.5 & 141 & 26.8 & 527 & 75.0 \\
\hline Female & 70 & 39.8 & 33 & 18.8 & 34 & 19.3 & 39 & 22.2 & 176 & 25.0 \\
\hline
\end{tabular}

Table 1b. Distribution of demographic, work hours and shift characteristics, sleep duration and quality, and alertness/sleepiness by total accumulated break time prior to the injury. [ $95 \% \mathrm{Cl}=95 \%$ confidence Interval]

\begin{tabular}{|c|c|c|c|c|c|c|c|c|c|c|}
\hline & \multicolumn{2}{|c|}{ No break } & \multicolumn{2}{|c|}{$1-30$ minutes } & \multicolumn{2}{|c|}{$31-60$ minutes } & \multicolumn{2}{|c|}{$>60$ minutes } & \multicolumn{2}{|c|}{ Total } \\
\hline & Mean & $\begin{array}{c}95 \% \mathrm{Cl} / \\
\text { Range }\end{array}$ & Mean & $\begin{array}{c}95 \% \mathrm{Cl} / \\
\text { Range }\end{array}$ & Mean & $\begin{array}{c}95 \% \mathrm{Cl} / \\
\text { Range }\end{array}$ & Mean & $\begin{array}{c}95 \% \mathrm{Cl} / \\
\text { Range }\end{array}$ & Mean & $\begin{array}{l}95 \% \mathrm{Cl} / \\
\text { Range }\end{array}$ \\
\hline Age (years) & 31.4 & $30.1-32.6$ & 30.6 & $28.6-32.7$ & 31.2 & $29.6-32.8$ & 33.5 & $32.1-35.0$ & 31.8 & $31.0-32.6$ \\
\hline $\begin{array}{l}\text { Total weekly work } \\
\text { hours }\end{array}$ & 53.4 & $51.3-55.5$ & 58.6 & $56.0-61.3$ & 59.4 & $57.0-61.7$ & 53.5 & $51.8-55.2$ & 55.5 & $54.3-56.6$ \\
\hline Days per week & 6.3 & $6.2-6.4$ & 6.5 & $6.4-6.7$ & 6.5 & $6.3-6.6$ & 6.4 & $6.2-6.5$ & 6.4 & $6.3-6.5$ \\
\hline $\begin{array}{l}\text { Scheduled shift } \\
\text { length (hours) }\end{array}$ & 8.9 & $8.6-9.3$ & 9.2 & $8.9-9.6$ & 9.9 & $9.6-10.1$ & 10.3 & $10.0-10.7$ & 9.6 & $9.4-9.7$ \\
\hline $\begin{array}{l}\text { Sleep duration } \\
\text { preceding the injury } \\
\text { (hours) }\end{array}$ & 8.5 & $8.2-8.8$ & 8.6 & $8.1-9.0$ & 8.9 & $8.7-9.1$ & 8.3 & $8.0-8.7$ & 8.6 & $8.4-8.7$ \\
\hline $\begin{array}{l}\text { Sleep quality preced- } \\
\text { ing the injury score }\end{array}$ & 3.7 & $0.0-5.0^{\text {a }}$ & 3.8 & $2.0-5.0^{a}$ & 3.9 & $0.0-5.0^{\text {a }}$ & 3.7 & $1.0-5.0^{\text {a }}$ & 3.8 & $0.0-5.0$ \\
\hline $\begin{array}{l}\text { Alertness / sleepiness } \\
\text { preceding injury }\end{array}$ & 3.0 & $0.0-7.0^{\text {a }}$ & 3.1 & $0.0-9.0^{a}$ & 2.9 & $1.0-7.0^{\text {a }}$ & 3.2 & $1.0-8.0^{\text {a }}$ & 3.0 & $0.0-9.0$ \\
\hline
\end{tabular}

a Range. 
Sleep duration, sleep quality, and alertness/sleepiness

Among all workers, the mean total sleep duration was 8.6 (95\% CI 8.4-8.7) hours, which was similar across rest break time categories (table 1). However, mean sleep duration was significantly different across workers within different shift start time categories $(\mathrm{P}<0.001$, data not shown). For morning workers (06:00-13:59 hours), mean sleep duration was 8.7 hours. Compared with day workers, the mean sleep duration of afternoon workers (14:00-21:59 hours) was 42 minutes shorter (8.0 hours) while that of night workers (22:00-05:59 hours) was over 1.5 hours shorter (7.1 hours). The mean overall response for subjective sleep quality was 3.8 (95\% CI 3.7-3.8) suggesting that workers slept on average "quite well". With regards to how alert or sleepy the workers felt at the time of their injury, the mean response was 3.0 (95\% CI 2.9-3.1), suggesting they were generally "alert". Both sleep quality and alertness/sleepiness were similar across categories of accumulated rest break times.

\section{Effects of rest break on time-to-injury}

Table 2 presents the results for the full Cox regression model (without interaction terms) for time-to-injury by accumulated rest break category, evaluating as potential covariates: age, gender, total weekly work hours, day and time of injury, shift start time, shift duration, last sleep duration (hours) and sleep quality, alertness/ sleepiness, job control, and seven transient work-related exposures. Workers with no rest break worked a median of 2.0 hours before their injury occurred, whereas workers with rest break durations of 1-30, 31-60, and $>60$ minutes, worked significantly longer $(\mathrm{P}<0.001)$ into their work shift without injury $(5.4,5.5$, and 6 hours, respectively). Complete data on all variables was available for 622 workers (88.5\%). Age, gender, alertness/ sleepiness, job control, and most transient work-related factors were not statistically significant $(\mathrm{P}>0.05)$ and final estimates are presented in figure 2 after adjustment for only significant covariates (note: age and gender were forced into the final model).

\section{Effect modification by shift start time}

In the full model, a rest break of any duration led to significantly longer time into the work shift without injury than no rest break $(\mathrm{P}<0.001)$. There was also a statistically significant difference among workers with different shift starting times $(\mathrm{P}<0.001)$, specifically, among workers starting their shift in the morning or earlier in the day (06:00-13:59 hours) compared with those starting later in the afternoon or night (14:0005:59 hours). Thus, in evaluating effect modification
Table 2. Full model a to predict time-to-injury by categories of rest break duration using Cox regression. [HR=hazard ratio; $\mathrm{SE}=$ standard error; $95 \% \mathrm{Cl}=95 \%$ confidence interval]

\begin{tabular}{|c|c|c|c|c|c|}
\hline Main effect & $\begin{array}{l}\text { Median } \\
\text { time-to- } \\
\text { injury } \\
\text { (hours) }\end{array}$ & $\begin{array}{l}\text { Parameter } \\
\text { estimate }\end{array}$ & SE & $\mathrm{HR}$ & $95 \% \mathrm{Cl}$ \\
\hline \multicolumn{6}{|l|}{ Rest break duration } \\
\hline No break & 2.0 & 0 Referent & & & \\
\hline $1-30$ minutes & 5.42 & $-0.90^{b}$ & 0.14 & 0.41 & $0.31-0.54$ \\
\hline $31-60$ minutes & 5.54 & $-1.02^{b}$ & 0.12 & 0.36 & $0.29-0.46$ \\
\hline$>60$ minutes & 6.08 & $-0.90^{b}$ & 0.13 & 0.41 & $0.31-0.53$ \\
\hline \multicolumn{6}{|l|}{ Control variables } \\
\hline Age & & $-0.01^{c}$ & 0.01 & 1.00 & \\
\hline $\begin{array}{l}\text { Time of injury } \\
\text { (hour, minutes) }\end{array}$ & & $-0.11^{b}$ & 0.01 & 0.90 & \\
\hline $\begin{array}{l}\text { Total work hours } \\
\text { (weekly) }\end{array}$ & & $-0.02^{b}$ & 0.01 & 0.98 & \\
\hline $\begin{array}{l}\text { Scheduled shift } \\
\text { length (hours) }\end{array}$ & & $-0.17^{b}$ & 0.03 & 0.84 & \\
\hline Day of injury & & $-0.04 d$ & 0.02 & 0.96 & \\
\hline $\begin{array}{l}\text { Sleep duration } \\
\text { (prior to injury) }\end{array}$ & & $0.05^{d}$ & 0.02 & 1.05 & \\
\hline $\begin{array}{l}\text { Sleep quality } \\
\text { (prior to injury) }\end{array}$ & & $-0.21^{e}$ & 0.08 & 0.81 & \\
\hline $\begin{array}{l}\text { Alertness / } \\
\text { sleepiness } \\
\text { (at time of injury) }\end{array}$ & & $0.01^{c}$ & 0.03 & 1.00 & \\
\hline \multicolumn{6}{|l|}{ Gender } \\
\hline Male & Referent & & & & \\
\hline Female & & $0.01^{\mathrm{C}}$ & 0.10 & 0.99 & \\
\hline \multicolumn{6}{|l|}{ Shift start time } \\
\hline 06:00-13:59 & Referent & & & & \\
\hline $14: 00-05: 59$ & & $-0.96^{b}$ & 0.14 & 0.38 & \\
\hline \multicolumn{6}{|l|}{ Tracient factors ${ }^{f}$} \\
\hline None & Referent & & & & \\
\hline $\begin{array}{l}\text { Unusual perform- } \\
\text { ing equipment }\end{array}$ & & $-0.13^{c}$ & 0.09 & 0.88 & \\
\hline Unusual task & & $-0.01^{c}$ & 0.12 & 0.98 & \\
\hline Unusual method & & $-0.12^{c}$ & 0.12 & 0.89 & \\
\hline Feeling sick & & $0.07^{c}$ & 0.24 & 1.07 & \\
\hline Rushed & & -0.30 e & 0.11 & 0.74 & \\
\hline Distracted & & $0.24^{c}$ & 0.13 & 1.28 & \\
\hline Gloves & & $0.01^{c}$ & 0.09 & 1.00 & \\
\hline \multicolumn{6}{|l|}{ Job control $g$} \\
\hline Non-self-paced & Referent & & & & \\
\hline Self-paced & & $-0.14^{c}$ & 0.09 & 0.87 & \\
\hline
\end{tabular}

${ }^{a}$ Controlling for age, gender, total weekly work hours, injury time, injury day, shift start time, shift duration, workers last sleep duration and sleep quality, alertness/sleepiness, and tracient factors (including unusual performing equipment, unusual task, unusual method, feeling sick, rushing, distracted, wearing gloves), and job control with no interaction.

${ }^{\mathrm{b}} \mathrm{P}<0.00$.

${ }^{\mathrm{C}}$ Not significant as $\mathrm{P}<0.05$.

${ }^{d} \mathrm{P}<0.05$.

e $P<0.01$.

'Presence or absence of tracient factor at the time of the injury.

"Self-paced" means worker has control over the pace of work. Nonself-paced includes "machine-paced", "incentive-based", and "quota/ time-based". 


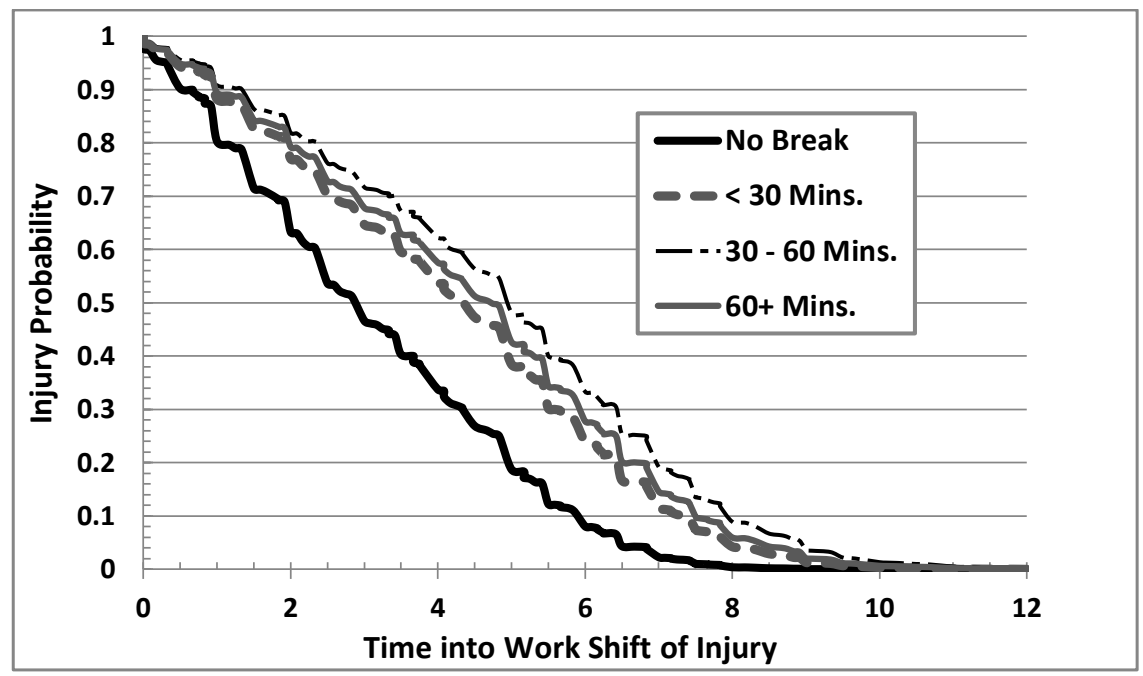

Figure 2. Final model: cumulative survival probability for time into the work shift of injury by rest break duration. Estimates calculated using Cox regression, adjusted for age, gender, total weekly working hours, shift start time, shift duration, day and time of injury, last sleep duration and quality, and rushing at the time of injury.
Table 3. Interaction model to predict time into the work shift of injury by rest break status and shift start time category. [HR=hazard ratio; $95 \% \mathrm{Cl}=95 \%$ confidence intervals]. Note: Statistically significant interaction $(P=0.0003)$ between rest break status and work shift start time (morning versus afternoon or night).

\begin{tabular}{|c|c|c|c|c|}
\hline \multirow[t]{2}{*}{$\begin{array}{l}\text { Rest break } \\
\text { status }\end{array}$} & \multicolumn{2}{|c|}{$\begin{array}{c}\text { Morning a } \\
(06: 00-13: 59)\end{array}$} & \multicolumn{2}{|c|}{$\begin{array}{l}\text { Afternoon or night a } \\
(14: 00-05: 59)\end{array}$} \\
\hline & HR & $95 \% \mathrm{Cl}$ & $\mathrm{HR}$ & $95 \% \mathrm{Cl}$ \\
\hline $\begin{array}{l}\text { No break(s) } \\
\text { reported }\end{array}$ & Referent &.. & Referent & .. \\
\hline $\begin{array}{l}\text { Reported at least } \\
\text { one rest break }\end{array}$ & 0.28 & $0.23-0.34$ & 0.61 & $0.41-0.90$ \\
\hline
\end{tabular}

by shift start time on injury risk by rest break status (see table 3), we found a strong, statistically significant interaction $(\mathrm{P}=0.0003)$ between rest break status (yes versus no) and shift start time (morning versus afternoon or night). Workers starting their shift earlier in the day, who reported at least one rest break, experienced a work-related injury significantly later into their shift than workers with no reported breaks [adjusted $\mathrm{HR}\left(\mathrm{HR}_{\mathrm{adj}}\right)$ 0.28, 95\% CI 0.23-0.34]. In comparison, workers starting shifts later in the afternoon or night experienced a statistically significant protective effect of their rest-break, however, the break effect was significantly weaker compared to workers with rest breaks who had started their shift earlier in the day $\left(\mathrm{HR}_{\mathrm{adj}}\right.$ $0.61,95 \%$ CI $0.41-0.90$ ).

\section{Discussion}

The results of this study examining a large sample of hospitalized workers in the PRC suggest that rest breaks of any duration have a significant effect on delaying the onset of a work-related traumatic injury. That is, workers reporting rest breaks were able to work significantly longer into their work shift without an injury than those with no rest break. Significant covariates included total work hours, time and day of injury, shift start time, shift duration, last sleep duration (hours), and sleep quality. Alertness/sleepiness was, however, not significant. Although, we expected alertness/sleepiness at the time of the injury to be significant, there is some evidence that shift workers habituate to a lower level of wellbeing (34). Thus, the self-reported subjective ratings of alertness/sleepiness reported by potentially fatigued workers may overestimate the actual level. Additionally, a statistically significant interaction between rest break status and shift start time was observed. Therefore, workers starting shifts later in the afternoon or night experienced a statistically significant protective effect of their rest break, however, importantly the break effect was significantly weaker compared to workers who had breaks but started their shift earlier in the day.

Our findings are consistent with those of Tucker et al (22-24), who reported decreases in work-related injury risk after a rest break, and Arlinghaus et al (27) who demonstrated that workers with longer accumulated rest break durations worked longer into their workday without injury than both those with no rest breaks or shorter breaks (1-15 minutes: $\mathrm{HR}_{\text {adj }} 0.60,95 \%$ CI $0.44-0.83$; 16-30 minutes: $\mathrm{HR}_{\text {adj }} 0.50,95 \%$ CI $0.33-0.75$; $>30$ minutes: $\left.\mathrm{HR}_{\text {adj }} 0.34,95 \% \mathrm{CI} 0.23-0.51\right)$. We observed a significant difference only in the time-to-injury in 
comparing workers with and without a rest break. However, injury onset time occurred on average 30 minutes earlier for workers with shorter breaks (1-30 minutes) compared to those with longer breaks ( $>60$ minutes). A possible key difference between the two studies is that Arlinghaus et al (27) were able to examine shorter break intervals (ie, 15 minutes). Clustering of break-time durations in our study led to sample size limitations in developing similar cut-off points, however, when we evaluated rest break duration as a continuous variable in a similar Cox regression model (without interaction terms), we observed a highly statistically significant $(\mathrm{P}<0.0001)$ slope parameter estimate $\left[B_{1}-0.27\right.$, standard error (SE) 0.07 or $\mathrm{HR}_{\text {adj }} 0.77,95 \%$ CI $\left.0.67-0.97\right]$.

A unique and important finding of this study is the statistically significant effect modification of rest break status by shift starting time, in which workers with a rest break during the morning shift or early afternoon (06:00-13:59 hours) experienced their injury significantly later in their work shift than those starting work later in the afternoon or night (14:00-05:59 hours). In the latter case, although there was a protective effect, it was significantly weaker than what was observed for workers starting their shift in the morning. Perhaps the effect moderation by time of day (circadian) is due to differences in time from a worker's last sleep to the start of his shift and differences in sleep duration, which may contribute as strongly to a restorative effect as a rest break later in the day. This is supported by the finding that workers with later shift starting time had a significantly shorter $(\mathrm{P}<0.001)$ mean sleep duration. This may suggest that it is especially important for afternoon and night workers to have additional rest breaks (or breaks of longer duration) since their sleep may be both further in time from their previous sleep and of shorter duration.

This study has several limitations and strengths. In the case of workers reporting an injury later into their work shift, there may have been more person-time to have rest breaks, thus potentially overestimating the protective effects of a rest break. In an attempt to correct for this, total rest break duration for each worker was subtracted from their time-to-injury for the analysis. Scheduled shift lengths also differed slightly across the rest break categories (see table 1), however this variable was statistically adjusted for in the final model. With regards to the specific activity occurring during the rest breaks, there was no additional information as to whether the worker used this break time to obtain recuperative rest or participate in other activities, although the impact on delaying the time-to-injury suggests it was recuperative.

Another potential limitation is that these data are from a case-crossover study $(6,29,33)$, which is a within person design and there are no uninjured controls to compare our results. This self-matched design controls measured and unmeasured confounders that do not vary within an individual over a short time period (ie, within a shift), however there may be confounding by multiple correlated unmeasured transient factors that impact the effect of a rest break on the time-to-injury $(29,33)$. For example, if a worker was fatigued and concurrently rushing while conducting the task at the time of their injury, this would remain confounded. Also this study relied on each subject's recall of their rest break times and other information. However, an important strength is the relatively short period of time between the work injury and the follow-up interview of the hospitalized worker (median of four days). Recall within four days of an injury has been previously shown to provide relatively reliable estimates of self-reported work exposure (35). Other strengths include the wide variety of occupational settings in which the injured workers in this study were employed, allowing for an examination of the potential effects of rest breaks across a heterogeneous group of workers.

In conclusion, the results of this study suggest that rest breaks have a significant effect on delaying the onset time of a work-related injury, which may have significant safety implications both in the PRC and other countries. In May of 2012, the Ministry of Human Resources and Social Security in the PRC issued draft rules on working hours for consultation. With regards to rest periods ("breaks"), two conditions were proposed. The first proposes "rest periods during a workday must be included in the calculation of working hours", in addition, the draft measures also prescribe compulsory rest periods of "no less than 20 minutes for every 4 hours of work and 10 minutes for every 2 hours of driving." In the US, laws and requirements regarding rest breaks vary by state; however most employers do offer short breaks (usually lasting 10-20 minutes for every 4 hours worked). Similarly, in the EU under the Working Time Directive 2003/88/EC (36), a worker is entitled to an uninterrupted break of 20 minutes when daily working time is $>6$ hours. The findings of this study support the use of rest breaks during a work shift, along with other proposed measures to delay the onset time of a workrelated injury and potentially counteract the effects of work fatigue $(36,37)$ as a means of obtaining recuperative rest and enhancing worker safety.

\section{Acknowledgments}

The authors are grateful to Drs Mary Lesch and Michelle Robertson for their comments on the draft of this paper. We also thank Liuzhou Municipal Center for Disease Control and Prevention, Ningbo No 6 Hospital, and Wuxi Municipal Center for Disease Control and Prevention for providing resources. The Liberty Mutual 
Research Institute for Safety and the Guangxi Science Foundation, PRC, (No. 0542114) supported this study.

\section{References}

1. $\mathrm{Hu} \mathrm{G}$, Baker TD, Li G, Baker SP. Injury control: an opportunity for China. Injury Prev. 2008;14:129-30. http:// dx.doi.org/10.1136/ip.2007.017822.

2. Fitzharris M, Yu J, Hammond N, Taylor C, Wu Y, Finfer S, Myburgh J. Injury in China: a systematic review of injury surveillance studies conducted in Chinese hospital emergency departments. BMC Emergency Medicine. 2011;11:18. http:// dx.doi.org/10.1186/1471-227X-11-18.

3. Li L, Liu X, Choi BC, Lu Y, Yu M. A descriptive epidemiological study on the patterns of occupational injuries in a coastal area and a mountain area in Southern China. BMJ Open. 2012;2:(3).

4. Yu W, Yu IT, Li Z, Wang X, Sun T, Lin H, Wan S, Qiu H, Xie S. Work-related injuries and musculoskeletal disorders among factory workers in a major city of China. Accid Anal Prev. 2012;48:457-63. http://dx.doi.org/10.1016/j. aap.2012.03.001.

5. Jin K, Lombardi DA, Courtney TK, Sorock GS, Li M, Pan R, Wang X, Lin J, Liang Y, Perry MJ. Patterns of work-related traumatic hand injury among hospitalised workers in the People's Republic of China. Inj Prev. 2010;16(1):42-9. http:// dx.doi.org/10.1136/ip.2008.019737.

6. Jin K, Lombardi DA, Courtney TK, Sorock GS, Li M, Pan R, Wang X, Lin J, Liang Y, Perry MJ. A case-crossover study of work-related acute traumatic hand injuries in the People's Republic of China. Scand J Work Environ Health. 2012; 38(2):163-70. http://dx.doi.org/10.5271/sjweh.3262.

7. Williamson A, Lombardi DA, Folkard S, Stutts J, Courtney TK, Connor JK. The link between fatigue and safety. Accid Anal Prev. 2011;34:498-515. http://dx.doi.org/10.1016/j. aap.2009.11.011.

8. Folkard S, Lombardi DA. Modeling the impact of the components of long work hours on injuries and "accidents". Am J Ind Med. 2006;49:953-63. http://dx.doi.org/10.1002/ ajim.20307.

9. Folkard S, Lombardi DA, Tucker PT. Shiftwork: safety, sleepiness and sleep. Ind Health. 2005;43:20-3. http://dx.doi. org/10.2486/indhealth.43.20

10. Folkard S. Black times: temporal determinants of transport safety. Accid Anal Prev. 1997;29:417-30. http://dx.doi. org/10.1016/S0001-4575(97)00021-3.

11. Hänecke K, Tiedemann S, Nachreiner F, Grzech-Sukalo H. Accident risk as a function of hour at work and time of day as determined from accident data and exposure models for the German working population. Scand J Work Environ Health. 1998;24 Suppl 3:43-8.

12. Lombardi DA, Sorock GS, Hauser R, Nasca PC, Eisen EA, Herrick RF, Mittleman MA. Temporal factors and the prevalence of transient exposures at the time of an occupational traumatic hand injury. J Occup Environ Med. 2003;45:832-40. http://dx.doi.org/10.1097/01.jom.0000083030.56116.1a.

13. Nachreiner F, Akkermann S, Haenecke K. Fatal accident risk as a function of hours into work. In: Hornberger S, Knauth P, Costa G, Folkard S, editors. Shiftwork in the 21st Century. Frankfurt am Main: Peter Lang; 2000. p. 19-24.

14. Wagstaff AS, Sigstad Lie JA. Shift and night work and long working hours - a systematic review of safety implications. Scand J Work Environ Health. 2011;37:173-85. http://dx.doi. org/10.5271/sjweh.3146.

15. Dababneh AJ, Swanson N, Shell RL. Impact of added rest breaks on the productivity and well-being of workers. Ergonomics. 2001;44(2):164-74.

16. Faucett J, Meyers J, Miles J, Janowitz I, Fathallah F. Rest break interventions in stoop labor tasks. Appl Ergon. 2007;38(2):219-26. http://dx.doi.org/10.1016/j. apergo.2006.02.003.

17. Galinsky TL, Swanson NG, Sauter SL, Hurrell JJ, Schleifer LM. A field study of supplementary rest breaks for data-entry operators. Ergonomics. 2000;43(5):622-38. http://dx.doi. org/10.1080/001401300184297.

18. Henning RA, Jacques P, Kissel GV, Sullivan AB, AlterasWebb SM. Frequent short rest breaks from computer work: effects on productivity and well-being at two field sites. Ergonomics. 1997;40(1):78-91. http://dx.doi. org/10.1080/001401397188396.

19. McLean L, Tingley M, Scott RN, Rickards J. Computer terminal work and the benefit of microbreaks. Appl Ergon. 2001;32(3):225-37. http://dx.doi.org/10.1016/S00036870(00)00071-5.

20. Neri DF, Oyung RL, Colletti LM, Mallis MM, Tam PY, Dinges DF. Controlled breaks as a fatigue countermeasure on the flight deck. Aviat Space Environ Med. 2002 Jul;73(7):654-64.

21. Sallinen M, Holm J, Hirvonen K, Härmä M, Koskelo J, Letonsaari $\mathrm{M}$, et al. Recovery of cognitive performance from sleep debt: do a short rest pause and a single recovery night help? Chronobiol Int. 2008;25(2):279-96. http://dx.doi. org/10.1080/07420520802107106.

22. Tucker P. The impact of rest breaks upon accident risk, fatigue and performance: a review. Work and Stress. 2003;17(2):12337. http://dx.doi.org/10.1080/0267837031000155949.

23. Tucker P, Folkard S, Macdonald I. Rest breaks and accident risk. Lancet. 2003;361:680. http://dx.doi.org/10.1016/S01406736(03)12566-4.

24. Tucker P, Lombardi D, Smith L, Folkard S. The impact of rest breaks on temporal trends in injury risk. Chronobiol Int. 2006;23:1423-34. http://dx.doi. org/10.1080/07420520601070315.

25. Macdonald I, Smith L, Lowe SL, Folkard S. Effects on accidents of time into shift and of short breaks between shifts. Int J Occup Environ Health. 1997;3:2:S40-S5.

26. Holcroft CA, Punnett L. Work environment risk factors for injuries in wood processing. J Safety Res. 2009;40(4):247-55. http://dx.doi.org/10.1016/j.jsr.2009.05.001. 
27. Arlinghaus A, Lombardi DA, Courtney TK, Christiani DC, Folkard S, Perry MJ. The effect of rest breaks on time-to-injury - a study on work-related ladder-fall injuries in the United States. Scand J Work Environ Health. 2012;38(6):560-7. http://dx.doi.org/10.5271/sjweh.3292.

28. Jin K, Lombardi DA, Courtney TK, Sorock GS, Perry MJ, Chen $\mathrm{H}$, et al. The challenge of cross-cultural collaborative research: lessons learnt from a pilot case-crossover study of severe occupational hand trauma in the People's Republic of China. Inj Prev. 2007;13(2):133-6. http://dx.doi.org/10.1136/ ip.2006.012534.

29. Lombardi DA. The case-crossover study: a novel design in evaluating transient fatigue as a risk factor for road traffic accidents. Sleep. 2010;33(3):283-4.

30. Hosmer DW, Lemeshow S. Applied survival analysis. Regression modeling of time to event data. New York: John Wiley \& Sons, Inc.; 1999.

31. Kaplan EL, Meier P. Nonparametric Estimation from Incomplete Observations. J Amer Statist Assn. 1958;53:45781. http://dx.doi.org/10.2307/2281868.

32. Cox DR, Oakes D. Analysis of survival data. London, UK: Chapman Hall; 1984.
33. Sorock GS, Lombardi DA, Gabel CL, Smith GS, Mittleman MA. Case-crossover studies of occupational trauma: methodological caveats. Inj Prev. 2001;7(suppl 1):i38-42. http://dx.doi.org/10.1136/ip.7.suppl_1.i38.

34. Spelten E, Barton J, Folkard S. Have we underestimated shift workers' problems? Evidence from a "reminiscence" study. Ergonomics. 1993;36(1-3):307-12. http://dx.doi. org/10.1080/00140139308967886.

35. Lombardi DA, Sorock GS, Lesch MF, Hauser R, Eisen EA, Herrick RF, Mittleman MA. A reliability study of potential risk factors for acute traumatic occupational hand injuries. Am J Ind Med. 2002;42:336-4. http://dx.doi.org/10.1002/ ajim. 10120 .

36. Directive 2003/88/EC of the European Parliament and of the Council of 4 November 2003 concerning certain aspects of the organisation of working time, Official Journal L 299, 18/11/2003 P. 0009 - 0019 (2003).

37. Pallesen S, Bjorvatn B, Magerøy N, Saksvik IB, Waage S, Moen BE. Measures to counteract the negative effects of night work. Scand J Work Environ Health. 2010;36(2):109-20. http://dx.doi.org/10.5271/sjweh.2886.

Received for publication: 11 March 2013 